\title{
Bartın Halatçıyaması Mevki Engelsiz Parkı Peyzaj Tasarım Projesi
}

\author{
Asım Cenk ASLAN ${ }^{1}$, Nurhan KOÇAN ${ }^{2 *}$
}

\section{$\ddot{\mathbf{O} z}$}

Kent içerisinde konumlanmış yeşil alanların kente ve kentliye önemli çevresel, ekonomik ve sosyal faydaları vardır. Kentsel yeşil alanlar, kentteki yaşam kalitesini iyileştirmek üzere planlanmış olup günümüzde farklı kavramlarla yeşil kentler yaratılmasında rol oynamaktadırlar. Kentsel yeşil alanlar insanlara psikolojik fayda sağlayan kentlinin doğa ile iletişim kurduğu alanlardır. Biyoçeşitliliği yüksek doğal ekosistemler uluslararası düzeyde korunurken, kentte yaşam kalitesinin iyileştirilmesinde rol oynayan yeşil alanlara yönelik gerekli farkındalık henüz yaygınlaşmamıştır. Kentsel yeşil alanların bu önemini göz önünde bulunduran peyzaj mimarlığı disiplini, kentsel yeşil alanları etkin bir şekilde şekillendirmekte ve yeşil alan bilinci yaratmaktadır. Bunun için kentsel yeşil alan plan ve tasarımları ile yeşil alanlar günlük yaşantıya dahil edilmektedir. Bu kapsamda çalışmada Bartın il merkezi Halatçıyaması mevkiinde güncel durumda boş olan alan engelli kullanıcılara yönelik planlama öğelerinin de içinde bulunduğu bir örnek alan olarak seçilmiştir. Çalışmada bölgenin isteklerine uygun olarak eskiz çalışmaları ile tasarım alternatifleri üretilmiş ve daha sonrasında bu tasarımlar Autocad 2021 programı kullanılarak proje taslağı oluşturulmuştur. Peyzaj tasarım projesinin nihai hali, SketchUp 2020 Pro 2020 yazılımı ile 3 boyutlu olarak modellenmiş ve Lumion 8.5 yazılımı ile projenin 3 boyutlu görselleştirme çalışmaları tamamlanmıştır. Çalışma sonucunda engelli kullanıcılara yönelik bir park kazanımı sağlanacak ve proje Bartın yerel yönetimi için fikir oluşturacaktır.

Anahtar Kelimeler: Kent parkı, Engelsiz park, Bartın, Peyzaj tasarım.

\section{The Landscape Design Project of Bartin Halatciyamasi Barrier Free Park}

\begin{abstract}
Green areas located within the city have significant benefits to the city and the urbanites such as environmental, economic and social. Urban green spaces have been planned to improve the quality of life in the city and today they play a role in creating green cities with different concepts. Urban green spaces are areas where citizens who provide psychological benefits and people communicate with nature. While natural ecosystems with high biodiversity are protected at the international level, the necessary awareness of green areas that play a role in improving the quality of life in the city has not yet become widespread. Considering this importance of urban green spaces, the landscape architecture discipline effectively shapes urban green spaces and creates green space awareness. For this, green areas are included in daily life thanks to the urban green space plans and designs. In this context, the study area was selected as a sample area that is in the Bartin city center in the district of Halatciyamasi. The area is currently vacant and the project was designed including planning elements for disabled users. In the study, design alternatives were produced with sketch studies in accordance with the wishes of the region, and then these designs were created using the Autocad 2021 program. The final version of the landscape design project was modeled in 3D with SketchUp 2020 Pro 2020 software and the 3D visualization of the project was completed with Lumion 8.5 software. As a result of the study, a park acquisition will be provided for disabled users and the project will create an idea for Bartin local administration.
\end{abstract}

Keywords: City park, Barrier-free park, Bartin, Landscape design.

\footnotetext{
${ }^{1}$ Bartın Üniversitesi Mühendislik Mimarlık ve Tasarım Fak. Peyzaj Mimarlı̆̆ı Bölümü Bartın, Türkiye, asimcenkaslan@gmail.com ${ }^{2}$ Bartın Üniversitesi Mühendislik Mimarlık ve Tasarım Fak. Peyzaj Mimarlığı Bölümü Bartın, Türkiye, nkocan@bartin.edu.tr
}

${ }^{1}$ https://orcid.org/0000-0002-9486-5333 ${ }^{2}$ https://orcid.org/0000-0001-9433-7007 


\section{Giriş}

Tarihin farklı dönemlerinde farklı sosyo-kültürel ve ekonomik işlevleri üstlenen kentler, işlevsel değişime uygun olarak her dönemin yaşam tarzı ve özelliklerini yansıtmakta ve dinamik bir nitelik taşımaktadır. Kent yaşamı içerisinde yer alan ve kamusal dış mekânlar olarak da adlandırılan açık yeşil alanlar tüm toplumun yararlanmasına olanak tanıyan mekânlardır. Kamusal dış mekânların sürdürülebilir kullanımı, mekânların kalitesi ve güvenliğinin yanı sıra erişilebilir ve tüm bireyler için eşit kullanım olanaklarına sahip olması ile mümkün olmaktadır (Kuter, 2017). Kent parkları; sayısız işlevleri olan, kentlilerin yaşam kaliteleri üzerinde önemli role sahip kamusal alanlardır. Parklar her yaştan ve fiziksel özelliğe sahip kullanıcılar tarafından kullanılmaktadır. Bu nedenle bu tür alanların evrensel tasarım kriterlerine uygun şekilde tasarlanması ve herkese hizmet etmesi gerekir. Yaşamının bir dönemi veya tümünde geçici veya sürekli olarak bağımsız hareket kısıtı olan bireyler için bu alanların kullanımı mekanın tasarımı ve donatılarının uygunluğuna bağlıdır. Engelli bireylerin sosyal yaşama katılımında park alanları ve yeşil alanlar şüphesiz çok önemlidir. Parklar, tüm kullanıcılara hizmet vermesi gereken kamusal alanlardan birisi olmasına rağmen çoğunlukla tasarımda yapılan eksikli ve hatalardan dolayı bu işlevi yeterli olarak yerine getirememektedir. Peyzaj tasarımı açısından engelli bireylerin gereksinimleri engelli olmayan bireylerle benzer olmakla birlikte "biçim" açısından bazı "özel” önlemler gerektirmektedir. Bu tür önlemleri kapsayarak tasarlanmış olan engelsiz parklar tüm kullanıcı grupları tarafından kullanılabilmekte ve böylece toplumsal bütünleşme sağlanmaktadır (Özdener, 2006).

Parklar insanların dinlenme, eğlenme ve sosyalleşme gibi gereksinimlerini karşılayan açık mekânlardır. Engelli bireyleri topluma kazandırmak, insanlarla olan sosyal ilişkilerini güçlendirmek ve yaşam seviyelerini yükseltmek için engelsiz park tasarımları büyük önem taşımaktadır. Bu nedenle kentlerdeki tüm bireylerin hiç bir ayrım yapılmaksızın eşit bir şekilde parklardan yararlanabilmesi için, parkların erişilebilir ve elverişli donanıma sahip olması gerekir.

Park alanlarında engelli bireylerin karşılaştıkları sorunlar çoğunlukla şöyledir (Çelik ve ark., 2015);

- Standartlara uygun olmayan ölçülerdeki (genişlik ve eğim) gezinti yolları, rampalar ve merdiven ve rampa eksikliği,

- Sert zemin kaplamalarında parlak ve kaygan malzeme kullanımı,

- Engelli bireylerin kullanımına uygun olmayan kent mobilyaları,

- Yanlış bitkisel tasarımlar ile bitkisel alanlarda sulama ve diğer bakım hatalarından kaynaklanan sorunlardan oluşmaktadır.

Bu gösteriyor ki aslında engeller vücudumuzda değil çevremizdedir. Çevremizdeki bu engeller, bireylerin park ve rekreasyon alanlarını kullanmalarını kısıtlamakta, bu durum ise onlara ruhsal ve 
bedensel yeni sorunlar yüklemektedir. Engelsiz park tasarımları, farklı etkinlik alanları ile tüm kullanıcılar için ulaşılabilir, erişilebilir, güvenli, bakımlı, rahat, konforlu ve çekici olmalıdır. Engelsiz parklar, her kullanıcı için erişilebilir ve bütün duyuları ile hissedilebilir nitelikte olmalıdır. Engelsiz park tasarımının temeli, park alanlarında mekânsal kullanım çeşitliliği ve bu mekanlarda kullanılan ürünlerin niteliğini kapsamaktadır (Şekil 1) (Çelik ve ark., 2015).

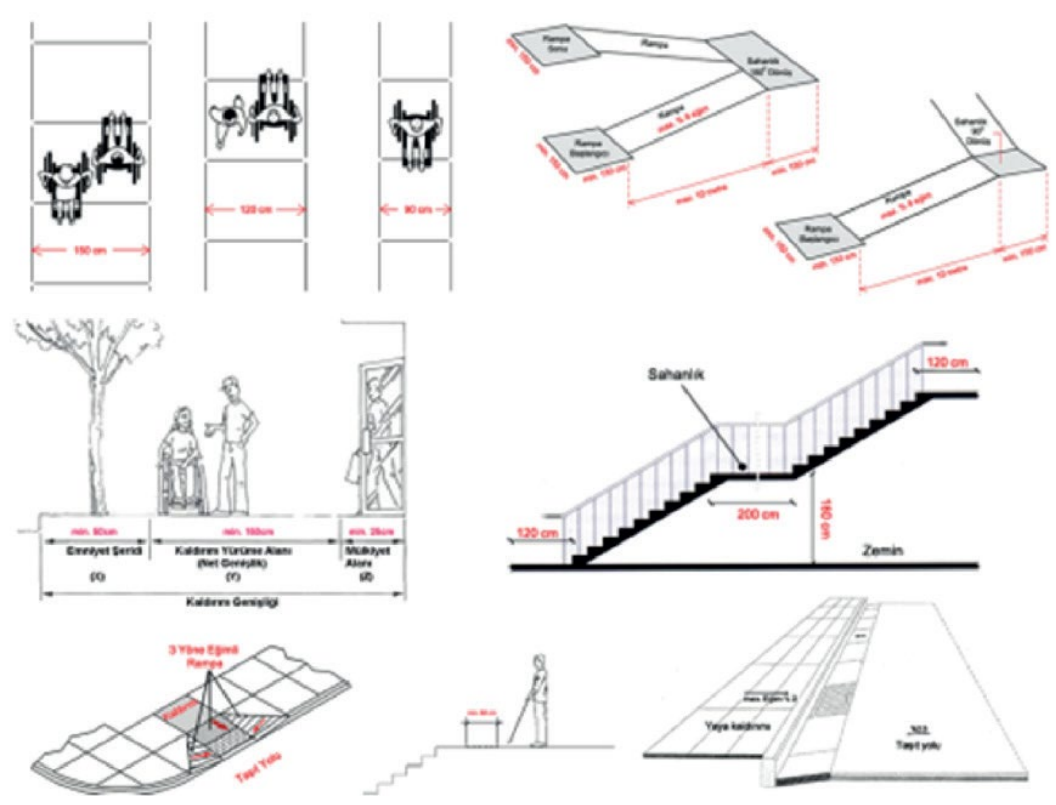

Şekil 1. Park içi yollar, rampa, merdivenlere ait standartlar (Engelsiz Kent, 2020)

Kentsel alanlarda yüksek düzeyde sosyal faydanın sağlanması için; farklı grupların toplumdan izole edilmesini önleyecek rekreasyon alanları ve yeşil alanların tasarımı, uygulanması ve yönetimi (Coles ve Caserio, 2001) ülkemizin de öncelikli konularından olmalıdır. Bu anlamda ülkemizde engelli bireylerin kullanabileceği “engelli parkları” yapılmıştır. Ancak iyi niyetle yapılmış olmasına rağmen engelli bireyleri izole eden, soyutlayan, ötekileştiren yönü ile bu uygulama sosyal hedefine ulaşmamıştır. Çelik ve Seyidoğlu (2010)'a göre engelli bireylerin \% 85'i toplumun her kesiminden insanların bir arada kullanabileceği engelsiz parkların yapılmasını istemektedir.

$\mathrm{Bu}$ çalışmada; engelsiz parklardaki açık alanlar, yarı açık alanlar, kent mobilyaları, bitkilendirme gibi peyzaj tasarım konuları, çeşitli literatür verilerinin analiz edilmesi ile değerlendirilmiş ve örnek bir alan üzerinde projelendirilmiştir. 


\section{Materyal ve Metot}

\subsection{Materyal}

Çalışma alanı Batı Karadeniz Bölgesi’nde Bartın ili sınırları içerisinde $32^{\circ} 22^{\prime}$ doğu boylamı, $41^{\circ} 40^{\prime}$ kuzey enlemi arasında yer almaktadır. Bartın ili doğuda Kastamonu, güneyde Karabük, batıda Zonguldak illeri ile kuzeyde Karadeniz ile komşudur. Bartın ilinin idari sınırları içerisinde; Merkez, Amasra, Kurucaşile ve Ulus olmak üzere dört ilçe yer almaktadır. Merkez ilçeye ait Arıt ve Kozcağız Beldeleri, Ulus İlçesine ait Kumluca Beldesi bulunmaktadır (Anonim, 1998). Çalışma alanı Bartın ili Merkez ilçesinde bulunan Demirciler Mahallesi, Halatçıyaması sokak adresindeki, 383 ada ve 364 parsel numaralı imar alanıdır (Şekil 2, 3).

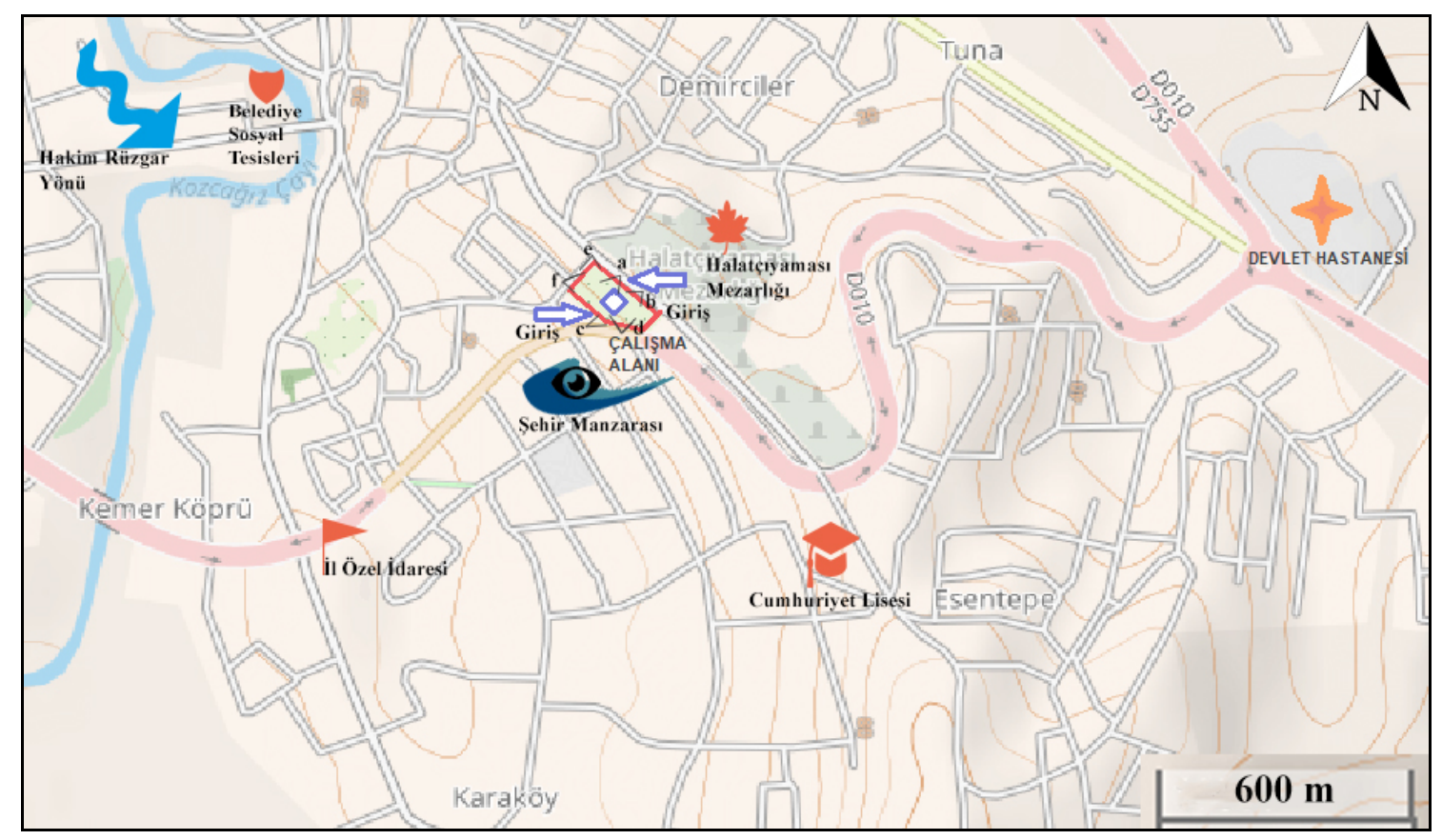

Şekil 2. Çalışma alanı sörvey paftası 


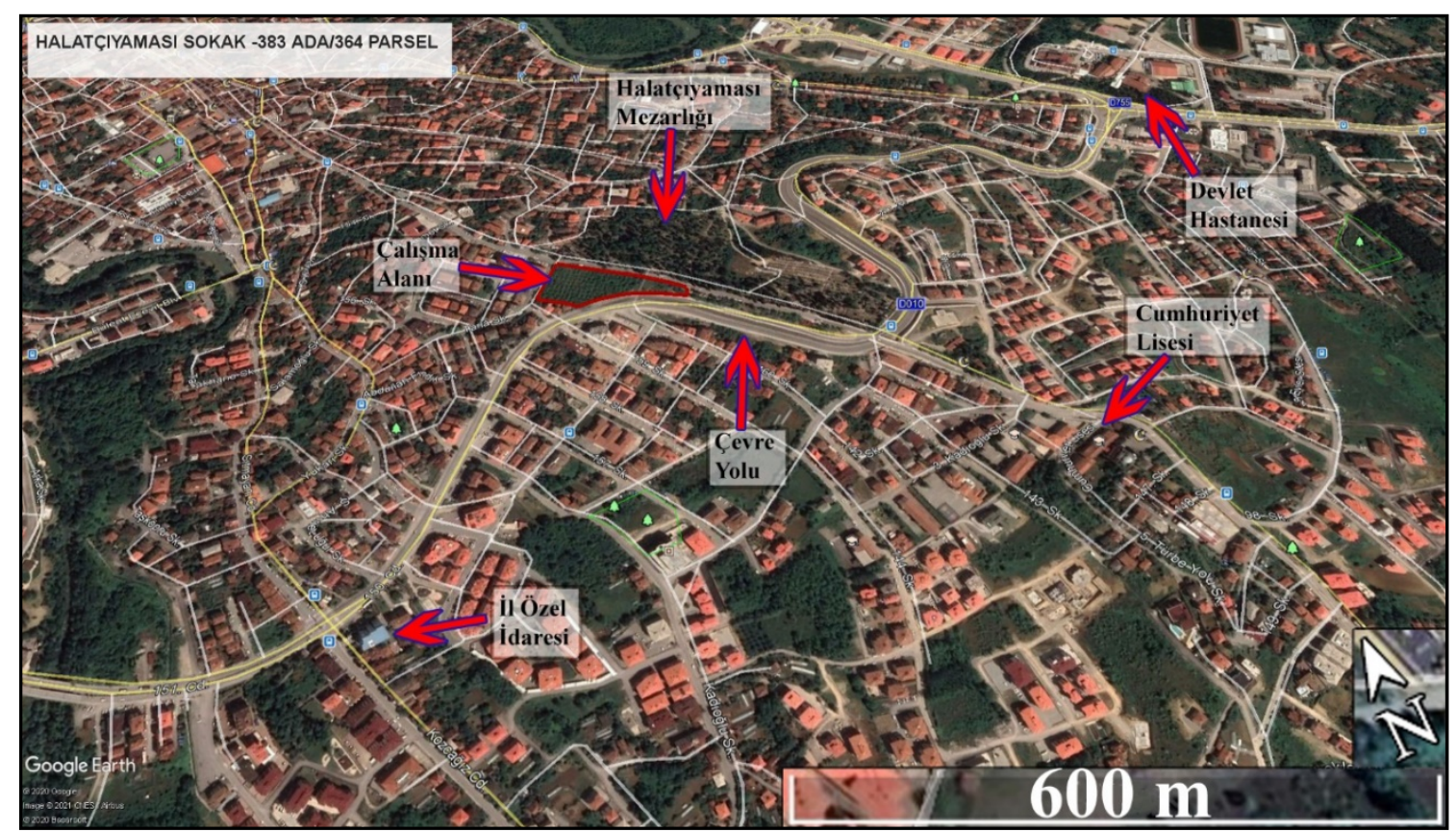

Şekil 3. Araştırma alanının konumu (Google Earth Pro, 2021)

Alan 8113, 76 m² dir (Parsel Sorgu, 2020). Alan Bartın'1 komşu illere bağlayan çevre yolu üzerinde eğimli bir topografyada bulunmaktadır. Alan kent merkezine yakındır. Alanın kuzeyinde Bartın kent mezarlığı bulunmaktadır. Alanın doğusunda bir adet kafe, 1 adet büfe, oturma alanları ve seyir terasları bulunmaktadır. Alan ilköğretim ve lise okullar bölgesindedir. Alanda mevcut durumda alt ve üst kotu bir merdiven sağlamaktadır. Çalışma alanında mevcut durumda herhangi bir altyapı ve üstyapı bulunmamaktadır. Alana erişim için kullanılan kuzey ile güney yolu arasında 9.5 metrelik kot farkı vardır (Şekil 3, 4).
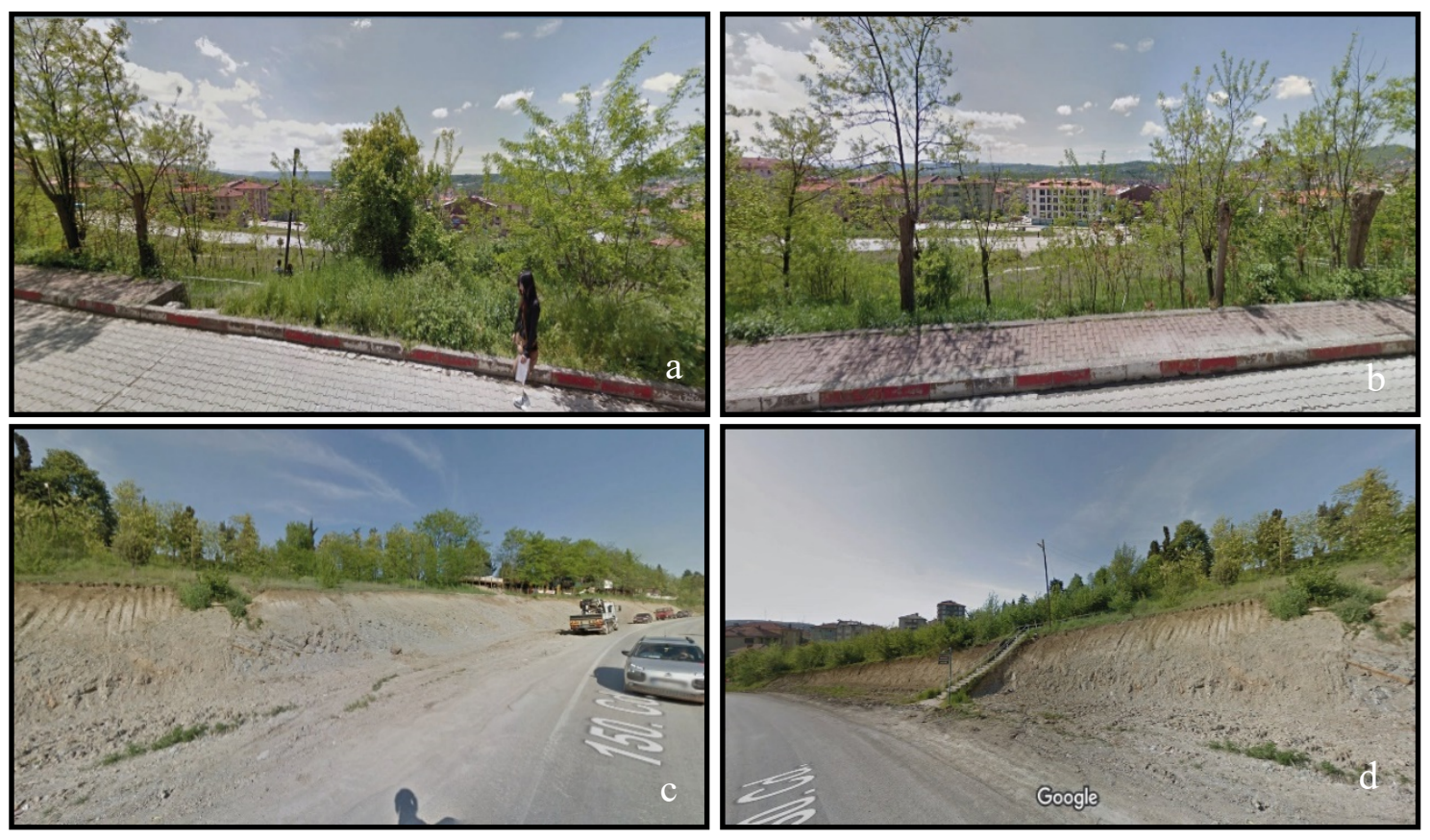

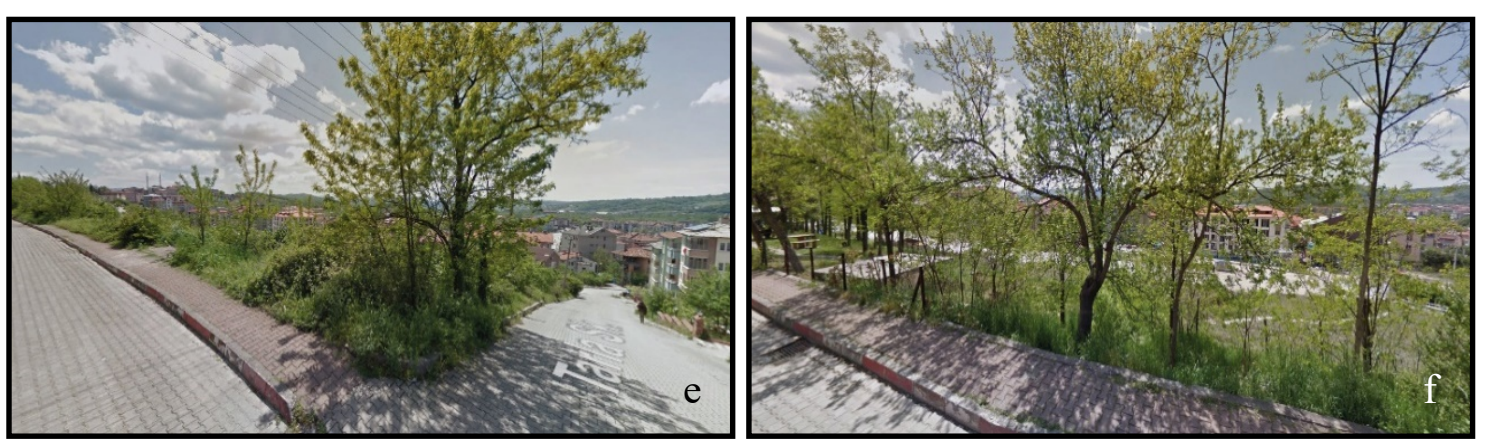

Şekil 4 (a-f). Alanın mevcut görüntüleri

Karadeniz Bölgesi'nde yer alan Bartın'da tipik deniz iklimi hakimdir. Yazlar serin, kışlar 1lık ve yağışlı geçer. Hemen hemen her mevsimde yağış alan Bartın, özellikle sonbahar ve kışın daha fazla yağış alır. Yağışlar yazları yağmur, kışları yağmur ve kar şeklindedir. Bartın'da yıllık ortalama sıcaklık 12,5 ${ }^{\circ} \mathrm{C}$ 'dir. Bartın'da yaz günleri sayısı yıllık 101,3 gün, ortalama kar yağışlı gün sayısı yıllık 19,3 gündür. Bartın'da ölçülen ortalama toplam yağış miktarı yıllık 1030 mm'dir. Bartın'da y1llık ortalama bağıl nem \%78'dir. Bartın'da hakim rüzgar yönü kuzeydoğudur (Anonim, 2006).

Bartın nüfusu 2019 yılı verilerine göre 198.249'dir. Bu nüfus, 97.908 erkek ve 100.341 kadından oluşmaktadır. Yüzde olarak ise nüfusun \%49,39'u erkek, \%50,61'i kadındır (Bartın Nüfus, 2020). 2013 verilerine göre Bartın’da 6571 engelli kişi bulunmaktadır (Engelli Sayıları, 2013). 2020 verilerine göre 28.663yaşlı birey yaşamaktadır (İstatistik Bülteni, 2020).

\subsection{Yöntem}

Araştırma alanında gerekli incelemeler yapılarak, alanın doğal ve kültürel verileri saptanmıştır. Alanda belirli noktalardan fotoğraf çekimleri yapılarak mevcut durum ortaya konulmaya çalışılmıştır. Yapılan gözlem ve incelemeler ile alanın mevcut durumu karşılaştırılarak alan kullanım esasları belirlenmiş, sorunlar tespit edilmiş ve buna yönelik alan kullanım ve tasarım esasları şekillendirilmiştir. Mevcut durumla ilgili sörveye dayanarak engelli kullanıcılara yönelik standartlara uygun bir tasarım yapılmıştır. Eskiz çalışmaları ile tasarım alternatifleri üretilmiş ve daha sonrasında bu tasarımlar taratılarak bilgisayar ortamına aktarılmış Autocad 2021 programı kullanılarak proje taslağı oluşturulmuştur (Şekil 5). Projenin nihai hali SketchUp 2020 Pro 2020 yazılımı ile 3 boyutlu olarak modellenmiş ve Lumion 8.5 yazılımı ile projenin 3 boyutlu görselleştirme çalışmaları tamamlanmıştır. 


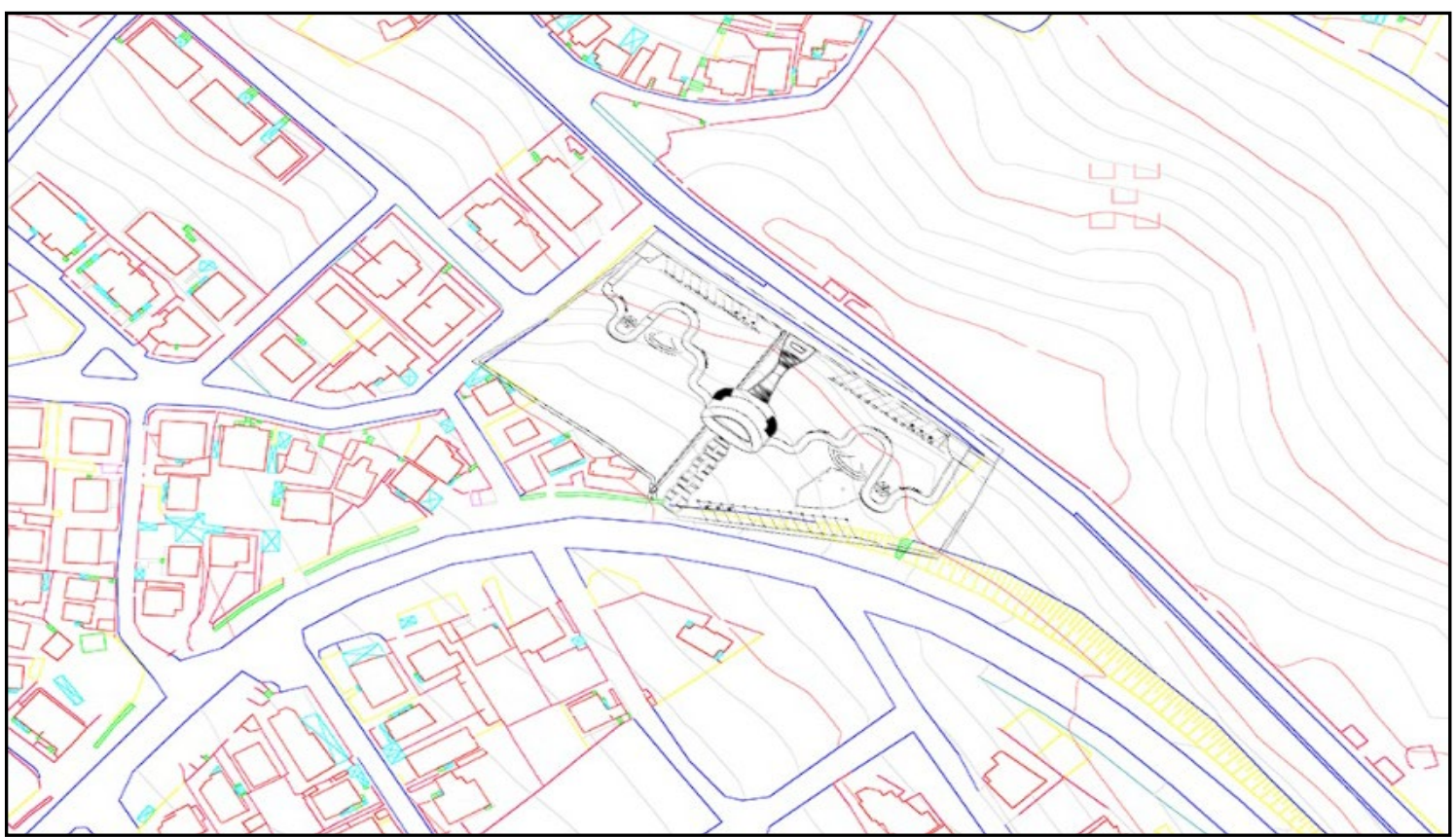

Şekil 5. Aurocad ortamında çalışma alanına yönelik tasarımın çizilmesi aşaması

\section{Araştırma Bulguları}

Peyzaj tasarım projesinde alanın kuzeye bakan bölümünden 3 adet normal, 1 adet engelliler için olmak üzere 4 farklı giriş düşünülmüştür. Engelliler için olan girişte tekerlekli sandalyeler için otomatik raylı sistem düşünülmüş ve alanı dikine kesen bir eksende konumlandırılmıştır. Alana ait eşyükselti verileri ile yapılan ölçümlerden alanın ortasında düşünülen meydan ile alanın kuzeyinde bulunan engelli rampası arasında \%33.3'lük bir eğim olduğu tespit edilmiştir. Meydan ile alanın güney girişi arasında ise \%11.3'lük bir eğim bulunmaktadır. Alanın güney girişinde bir otomatik raylı sistem düşünülmüştür. Bu sistemle engellilerin eğimli rampada alanın orta noktasında ve kuzeyinde bulunan kullanımlara rahat erişimi sağlanacaktır (Şekil 6,7,8,9).

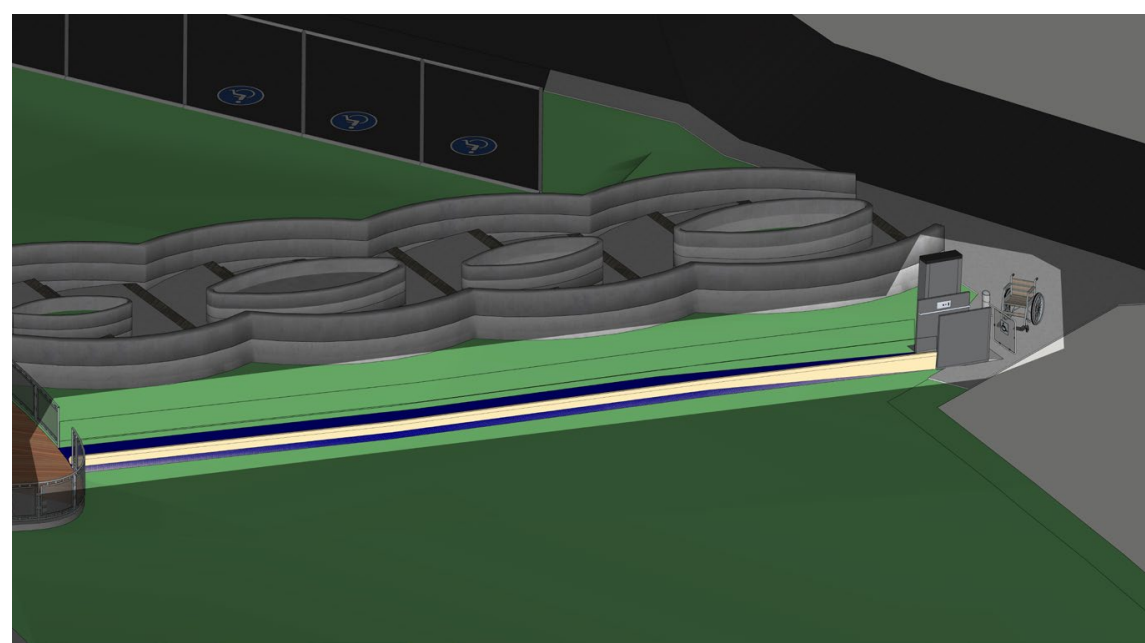

Şekil 6. Güney-meydan yönlü engelli raylı taşıma sistemi 


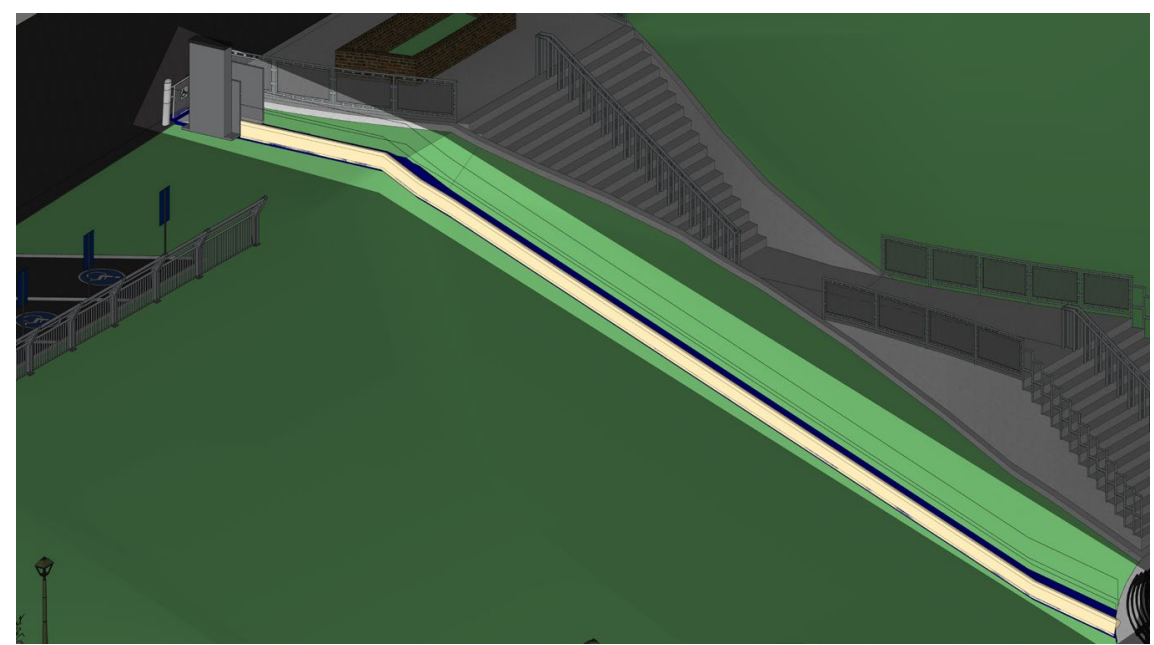

Şekil 7. Kuzey-meydan yönlü engelli raylı taşıma sistemi
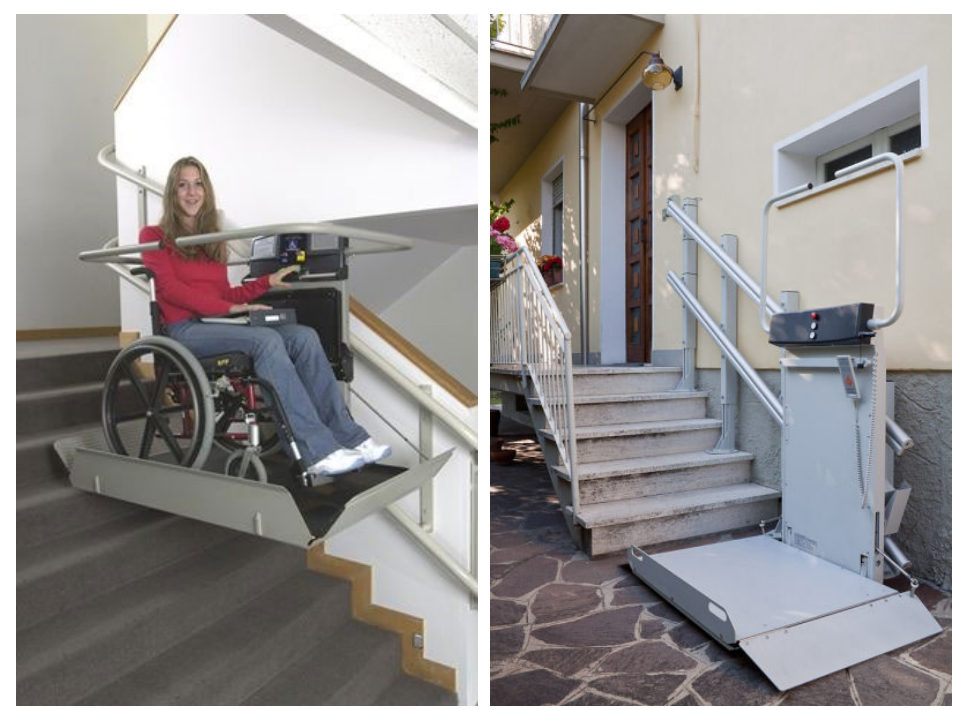

Şekil 8-9. Engelli asansörü örnekleri
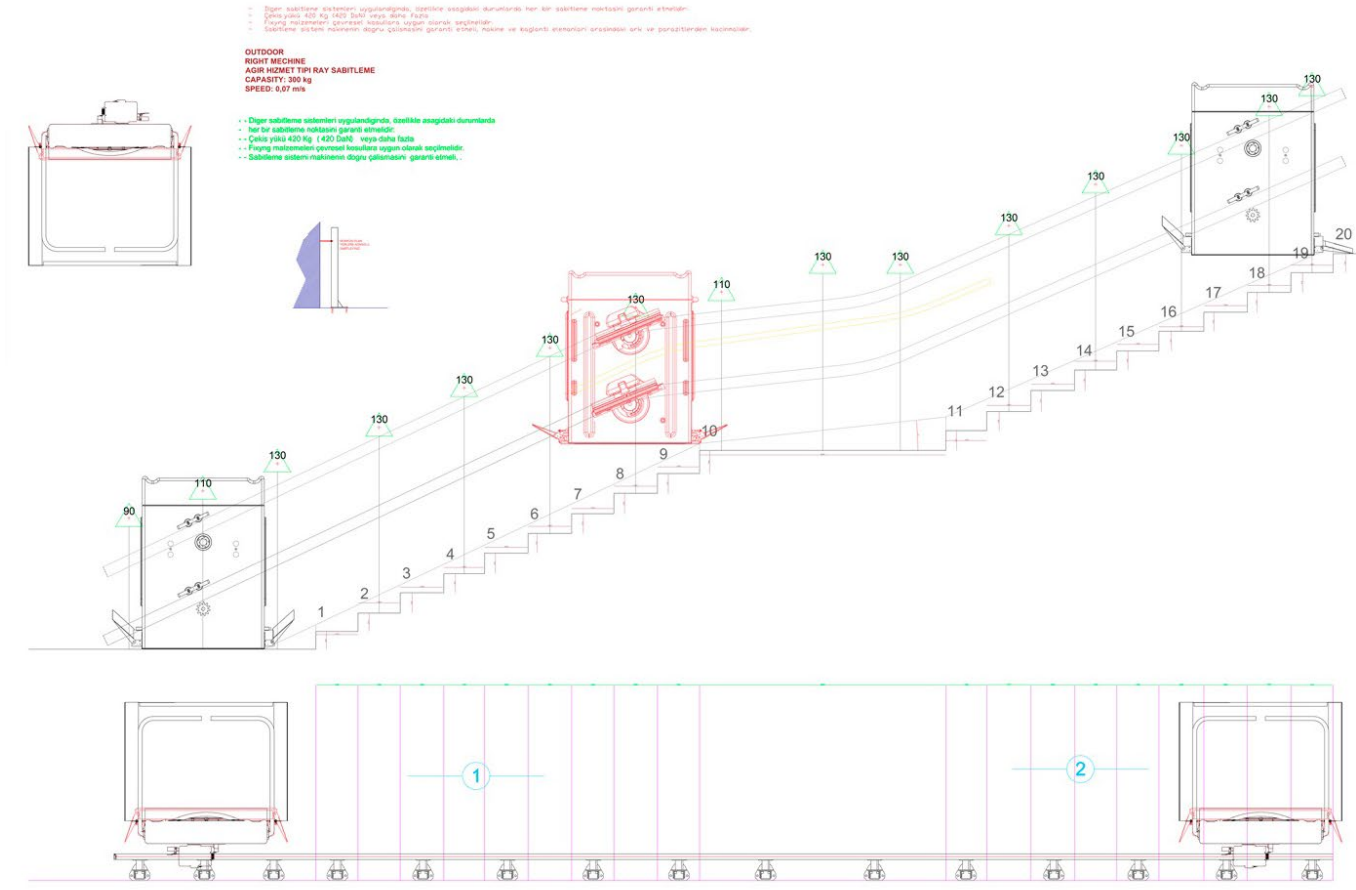

Şekil 10. Engelli asansörü teknik çizim detay 
Alanın kuzey ve güney tarafından geçen yol ile bağlantılı otoparklar düşünülmüştür. Alanın bulunduğu yer itibarı ile projelendirme sonrasında oluşacak yoğunluk düşünülerek 33 araçlık otopark alanının 9 adedi engelliler için ayrılmıştır. Uslu (2009) engellilerin bağımsız hareket edebilmesi için kamusal mekanların bitkisel tasarımında bazı hususlara dikkat edilmesi gerektiğini vurgulamıştır. Döşeme üzerinde tekerlekli sandalye hareketini engelleyecek meyve, kozalak, kırık dal parçaları ya da yere yakın dallanan ağaç türleri ile yüzlek köklü türler özellikle yürüme yolları üzerinde kullanılmamalıdır (örneğin; Pinus sp., Quercus sp., Aesculus sp. gibi). Dikenli türlerin (Rosa sp., Berberis sp. gibi) dikenleri, dal parçaları, yürüme yolu üzerinde ya da kenarında fark edemeyen bireylere batacağından dikkatli kullanılmalıdır. Yüzlek köklü türler (Salix sp., Acer sp. gibi) tekerlekli sandalye veya bastonun takılmasına neden olabilir. Projede yer alan bitkiler seçilirken çiçek ve yaprakları ile alerjenik olmayan, zehirli meyve ve çiçeklere sahip olmayan, dikensiz ve sivri uçlu dallar vermeyen türlerden olmasına dikkat edilmiştir. Bartın ilindeki iklim şartlarına uygun, az sulama ve bakım gerektiren bitkiler göz önüne alınarak bakım maliyeti düşürülmüştür. Alanın kuzey girişinde bisikletliler için bisikletlerini bırakabilecekleri park alanı düşünülmüştür.

Projeye ait tüm yapısal ve bitkisel elemanlar ihtiyaç listesi oluşturularak listelenmiştir (Tablo 1 ve Tablo 2). Projede alan kullanımları ve tasarımlarına ilişkin öneriler şekiller (Şekil 11-Şekil 20) üzerinde gösterilmiştir. Projede genel olarak simetrik bir tasarım anlayışı izlenmiştir.

Tablo 1. Donatı elemanı ihtiyaç listesi

\begin{tabular}{lcc}
\hline Donatı Adı & Adet & Kapladı̆̆ı Alan \\
\hline Beton yer döşemesi & - & $650 \mathrm{~m}^{2}$ \\
Asfalt-otopark döşemesi & - & $550 \mathrm{~m}^{2}$ \\
Ahşap yer döşemesi & - & $140 \mathrm{~m}^{2}$ \\
Engelli yolu & - & $60 \mathrm{~m}^{2}$ \\
Otomatik raylı sistem korkuluğu & - & $110 \mathrm{~m}$ \\
Engelli taşıma sistemi & 2 & - \\
Metal korkuluk & 100 & - \\
Aydınlatma elemanı & 6 & - \\
Beton oturma elamanı & 6 & - \\
Ahşap oturma elemanı & 2 & - \\
Metal pergola & 2 & - \\
6 köşeli kameriye & 2 & - \\
\hline
\end{tabular}


Tablo 2. Bitkisel materyal ihtiyaç listesi

\begin{tabular}{lll}
\hline Bitkinin Latince Adı & Bitkinin Türkçe Adı & Adet \\
\hline $\begin{array}{l}\text { Alumroot burgundy } \\
\text { Azalea rhododendron }\end{array}$ & Alumroot & 18 adet \\
İlex aquifolium & Açelya & 10 adet \\
& $\begin{array}{l}\text { Çobanpüskülü } \\
\text { (Ağaç) }\end{array}$ & 26 adet \\
Illex opaca & Çobanpüskülü (Çalı) & 6 adet \\
Lagerstroemia crape myrtles & Beyaz Oya Ağacı & 16 adet \\
Quercus pagoda & Pagoda Meşesi & 2 adet \\
Salix matsudana & Tirbişön Söğüdü & 2 adet \\
Acer rubrum & Kirmızı Akçaağaç & 8 adet \\
Fraxinus excelsior & Adi Dişbudak & 1 adet \\
Muhlenbergia capillaris & Pembe Pamuk Şekeri & - \\
& Çimi & \\
Helleborus orientalis & Bohça Otu & - \\
Cortaderia selloana & Pampas Otu & - \\
Miscanthus sinensis & Çin Gümüş Otu & - \\
Hedera hibernica & Sarmaşıklı Çit & 45 metre \\
\hline
\end{tabular}

Alanda eğimden dolayı teraslamalar yapılmış bu teraslarda oluşturulan istinat duvarları kademelendirilerek oturma duvarı şeklinde kullanılmıştır. Yine alanda kuzey tarafta yol kotunda ağaç altı oturma birimleri yapılmıştır. Duvarların soğuk görünümünü perdelemek için sarılıcı bitkiler tercih edilmiştir.

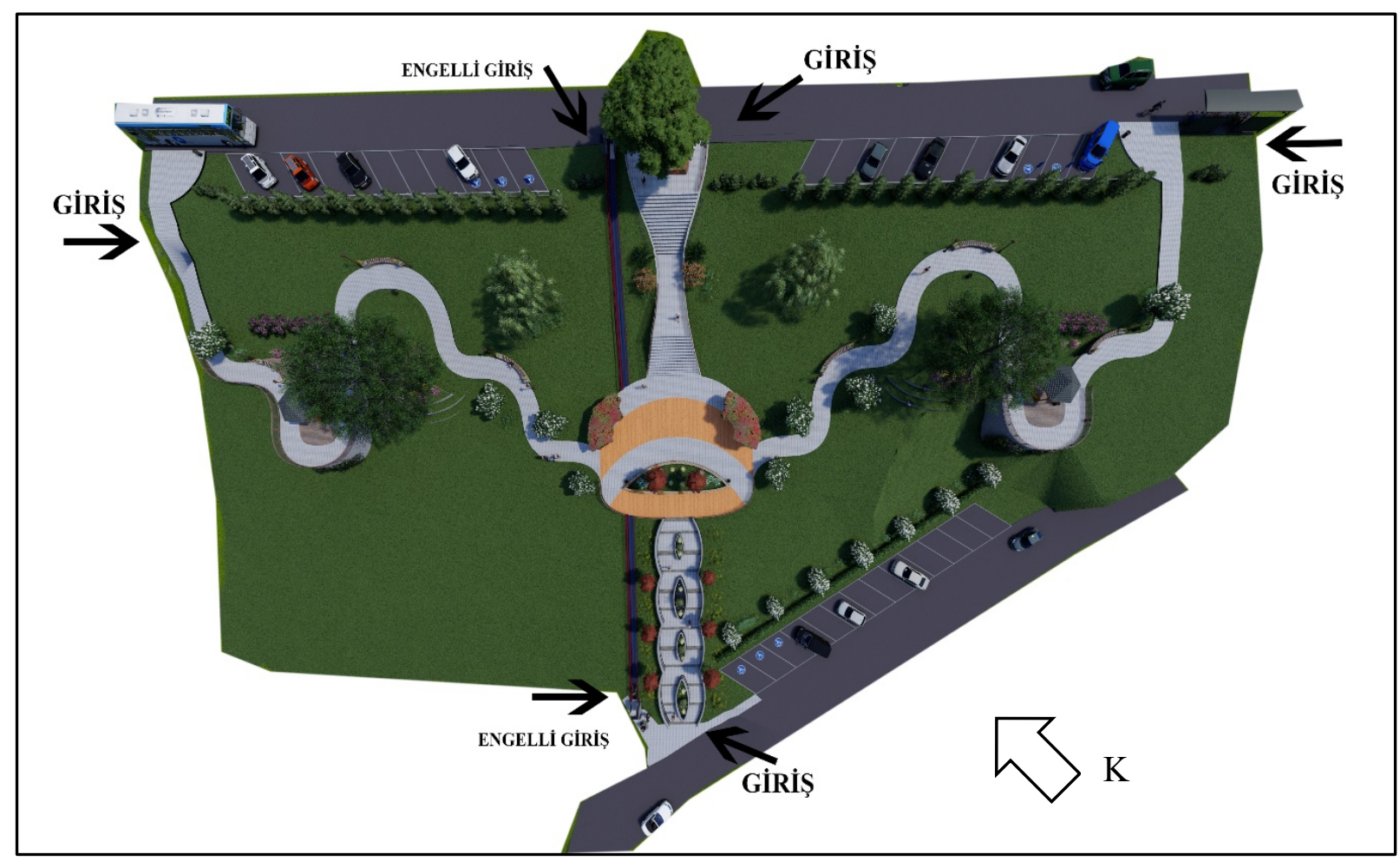

Şekil 11. Peyzaj tasarım projesi plan görünümü 


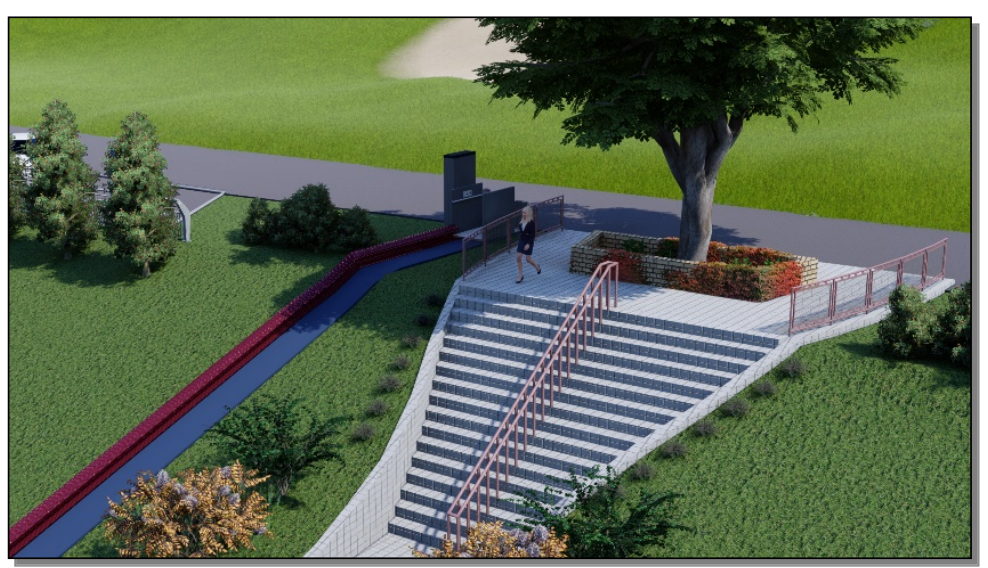

Şekil 12. Kuzey ana giriş perspektif görünümü

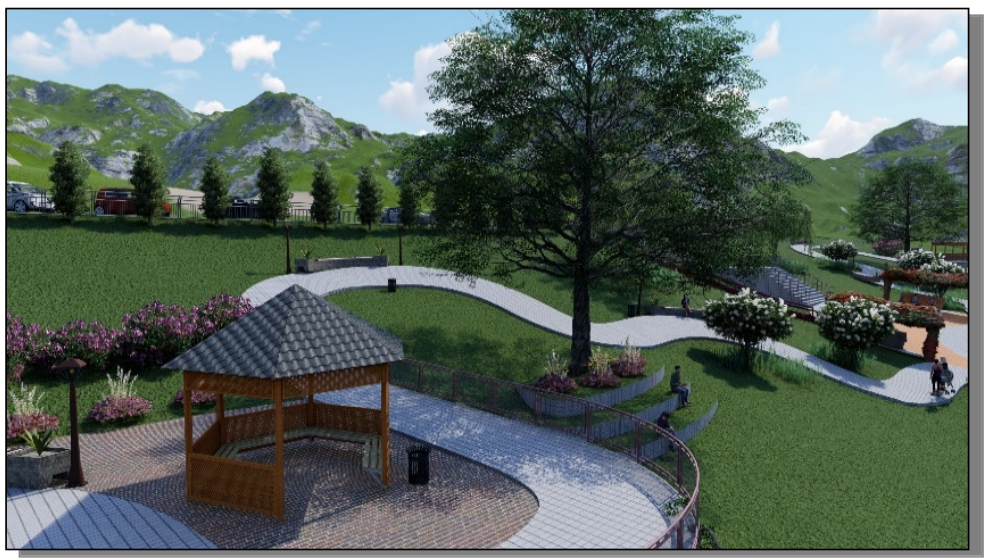

Şekil 13. Kameriye ve oturma alanı perspektif görünümü

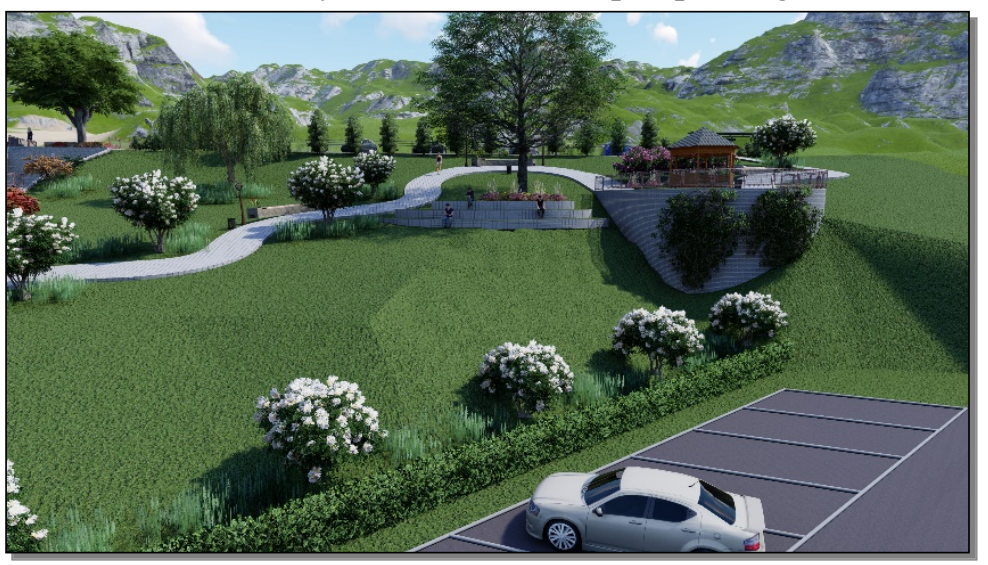

Şekil 14. Güney otoparkı ve kameriye perspektif görünümü 


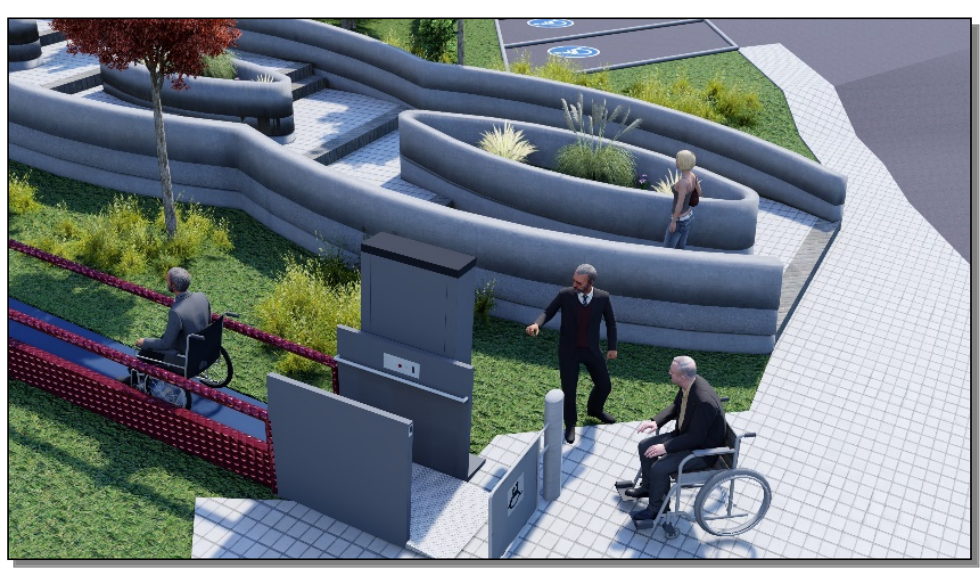

Şekil 15. Güney girişi ve otomatik raylı sistem perspektif görünümü

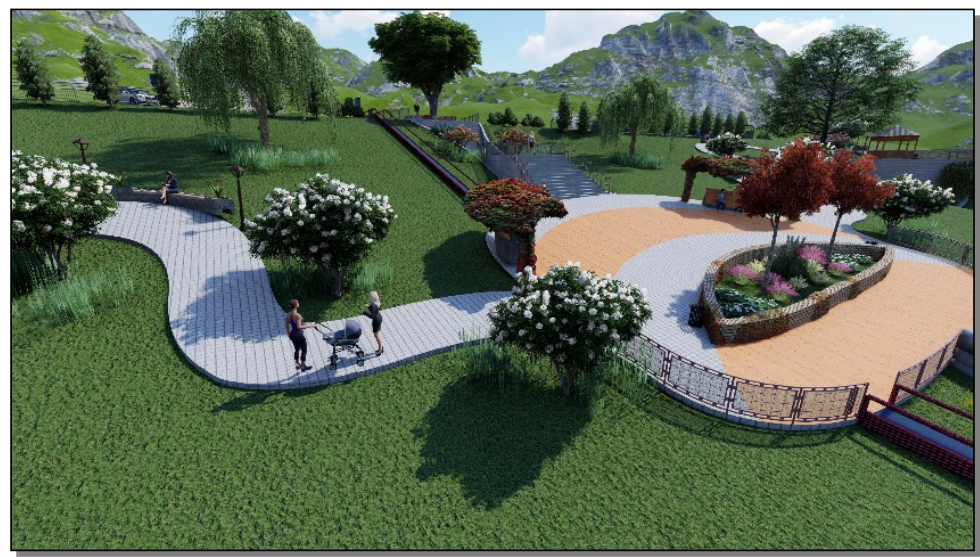

Şekil 16. Meydan peyzaj tasarımı perspektif görünümü

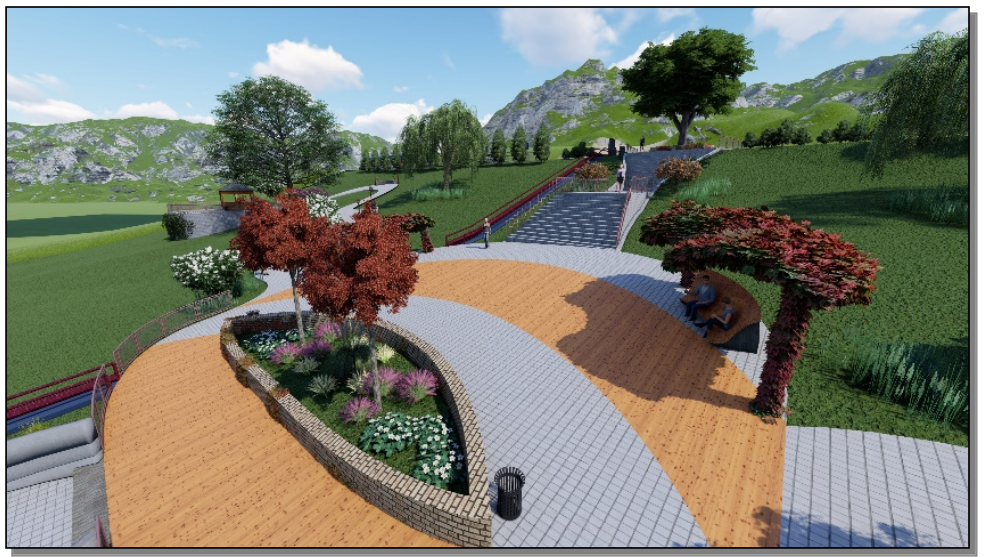

Şekil 17. Meydan bitkisel tasarımı perspektif görünümü

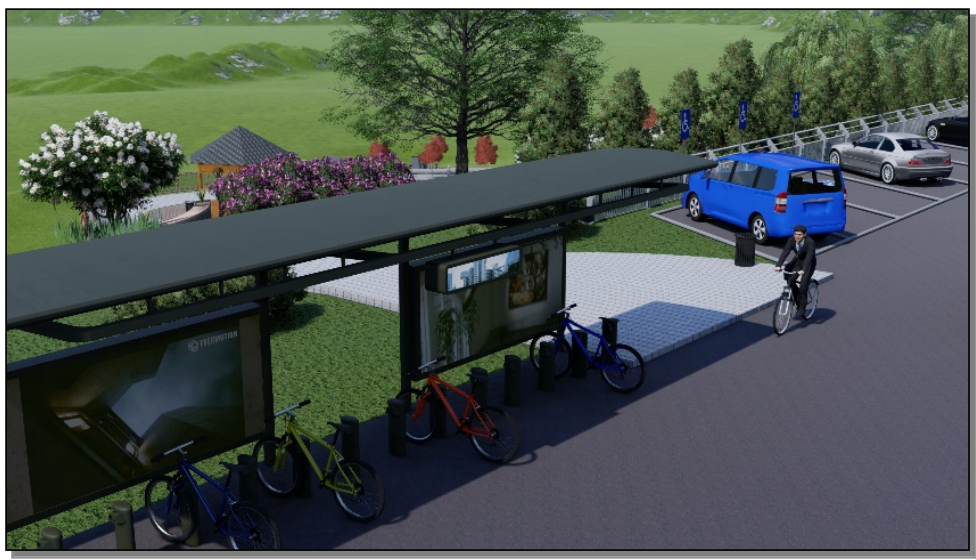

Şekil 18. Bisiklet parkı perspektif görünümü 


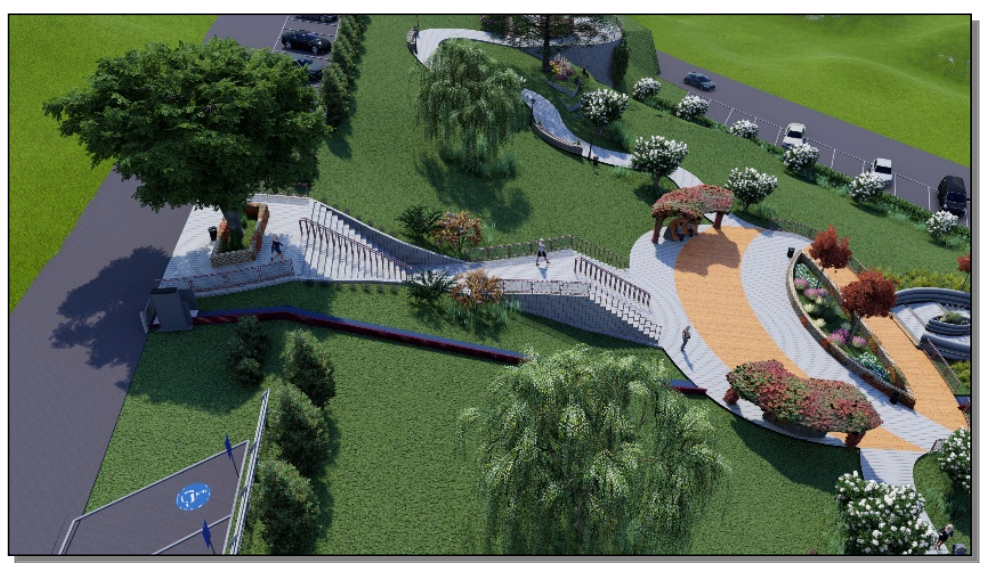

Şekil 19. Meydan ve kuzey girişi perspektif görünümü

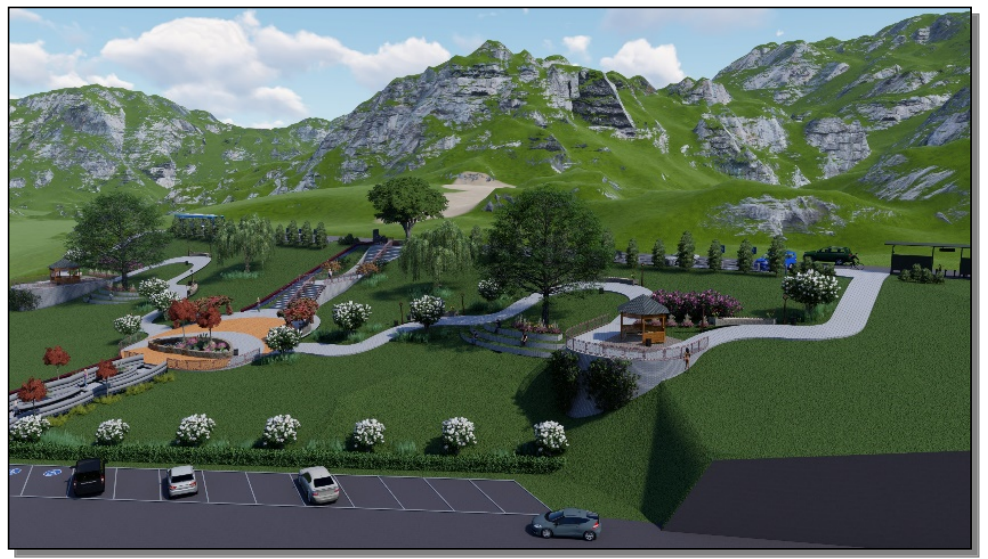

Şekil 20. Güney otopark1 ve alanın genel perspektif görünümü

\section{Sonuç ve Öneriler}

$\mathrm{Bu}$ çalışmada kent içinde konumu ile önemli bir yerde bulunan çalışma alanında kentsel kamusal bir kullanımın sağlanması için işlevsel ve estetik yönden uyumlu peyzaj tasarım önerileri geliştirilmiştir. Alan öncelikle engelli kullanıcılar düşünülerek tasarlanmıştır. Çalışma alanı Bartın’ı Karadeniz'de diğer illere bağlayan geçiş güzergahında olduğu için yol üzeri dinlenme alanı olarak da hizmet verecek ve kenti ziyaret eden veya geçiş durumunda olan kullanıcılara da dinlenme ortamı sağlayacaktır. Alanın kuzey girişi yüksek kotta olduğu için ziyaretçiler bu alandan kuşbakışı olarak şehri izleyip oturup dinlenebileceklerdir.

Alanın kullanımının öncelikle alana erişimle sağlanacağı düşüncesiyle hem alt kotta hem de üst katta araçla ve yaya olarak bağlantı sağlanmış ve otoparklar ile bisiklet park etme yerleri yapılmıştır. $\mathrm{Bu}$ şekilde oldukça işlek olan çevre yolunda alana giriş ve çıkışlar güvenli bir şekilde yapılabilecektir. Mevcut alanda, doğu yönünde mevcut işletmeler bulunmaktadır. Bu işletmeler çay bahçesi ve büfe içeren alandır. Dolayısıyla çalışma alanı bu alanın bitişiğinde olduğu için tekrar bir kafe, büfe gibi kullanımlar düşünülmemiş olup alanı toplumdan her kesimin rahatlıkla ve ücretsiz kullanması hedeflenmiştir. $\mathrm{Bu}$ düşünceyle alanda yapısal kullanımlardan kaynaklanan yeşil alan kaybı da azaltılmıştır. 
Çalışma alanını engelli bireylerin rahatlıkla kullanabilmesi için arazinin topografya çözümü, kullanımlara erişim ve donatı elemanlarının seçiminde standartlara uyulmuştur. Otomatik raylı sistem ise Bartın'daki mevcut park ve rekreasyon alanlarında olmayan bir uygulamadır. Projenin uygulanması durumunda kent için ilk olacaktır. Bu örnek uygulamanın başka alanlar için de teşvik edici olacağı düşünülmektedir. Çalışmanın sonucunda projenin uygulanması durumunda bu alanın fiziksel mekân kalitesi artacak ve atıl duran bu alan kamusal açık yeşil alan sistemine katılmış olacaktır. Çalışma ile kent halkı ve ziyaretçilere alternatif bir dinlenme alanı kazandırılmış olacaktır.

\section{Yazarların Katkısı}

Tüm yazarlar çalışmaya eşit katkıda bulunmuştur.

\section{Çıkar Çatışması Beyanı}

Yazarlar arasında herhangi bir çıkar çatışması bulunmamaktadır.

\section{Araştırma ve Yayın Etiği Beyanı}

Yapılan çalışmada araştırma ve yayın etiğine uyulmuştur.

\section{Kaynaklar}

Anonim. (1998). Cumhuriyetimizin 75. Yılında Bartın. İl Özel İdare Müdürlüğü, Bartın.

Anonim. (2006). Zonguldak, Bartın, Karabük Planlama Bölgesi 1/100000 Ölçekli Çevre Düzeni Planı Araştırma Raporu. JEO-TEK ve UTTA Ltd. İş. Ortaklığı, Ankara.

Bartın Nüfusu, (2020). https://www.nufusu.com/il/bartin-nufusu (Erişim Tarihi: 25.12.2020)

Coles, R., Caserio, M. (2001). Social Criteria for The Evaluation and Development of Urban Green Spaces. URGE (Urban Green Environment, Development of Urban Green Spaces to Improve) The Quality of (Life in Cities) and Urban Regions. EVK-4- ET-2000-00022.

Çelik, A., Ender, E., Seyidoğlu Akdeniz, N. (2015). Engelsiz Parklarda Peyzaj Tasarımı. Tarım Bilimleri Araştırma Dergisi, 8(2), 5-11. http://www.ijans.org/index.php/ijans/article/view/351

Çelik, A., Seyidoğlu, N. (2010). Problems faced by users with disabilities in access to urban outdoors: Kocaeli sample", African Journal of Agricultural Research, Vol. 5(24), pp. 3455- 3463.

Engelli Sayllar1, (2013). https://www.haberturk.com/gundem/haber/830504-iste-o-harita

Engelsiz Kent, (2020). http://engelsizkent.org/tasarim (Erişim Tarihi: 25.12.2020)

İstatistik Bülteni, (2020). Engelli ve Yaşlı Hizmetleri Genel Müdürlügü, https://www.ailevecalisma.gov.tr/media/42250/istatistik-bulteni-2020-mart.pdf

Kuter, N. (2017). Kamusal Dış Mekânlarda Engelliler İçin Tasarım: Ankara, Seğmenler Parkı Örneği. 3, 93110.

Özdener, N. (2006). Mardin'de özürlüler görmezden gelinemez. Kent ve Sağlık Sempozyumu, Bursa, Bildiri Özetleri Kitab1, s: 367-368.

Parsel Sorgu, (2020). https://parselsorgu.tkgm.gov.tr/ (Erişim Tarihi: 20.10.2020)

Uslu, A. (2009) Kentsel Peyzajda Yaşlı / Engelli İçin Bağımsız Hareket Olanağı ve Evrensel Tasarım Kavramı, Ufkun Ötesi Bilim Dergisi, Cilt 9 Sayı 1-2, s. 27-40. 